\title{
Can the CERAD neuropsychological battery be used to assess cognitive impairment in Parkinson's disease?
}

\author{
A bateria neuropsicológica do CERAD pode ser usada para avaliação cognitiva em \\ pacientes com doença de Parkinson? \\ Carlos Henrique Ferreira Camargo', Augusto Bronzini', Eduardo de Souza Tolentino', Camila Medyk', \\ Gustavo Leopold Schultz-Pereira
}

\begin{abstract}
The Consortium to Establish a Registry for Alzheimer's Disease (CERAD) neuropsychological battery was created to assess cognitive impairment in Alzheimer's disease (AD) but it is widely-used for various dementias. The aim of this study was to analyze the efficacy of using the CERAD battery in the assessment of patients with Parkinson's disease. Forty-nine patients with Parkinson's disease were divided into two groups (one with dementia and one without) using the Movement Disorder Society criteria for Parkinson's disease dementia. Cognitive deficits were assessed with the Clinical Dementia Rating Scale as the gold standard, and the CERAD. The ROC curve for the CERAD battery had an area under the curve $=0.989(95 \% \mathrm{Cl}=0.967-1, \mathrm{p}<0.0001)$. Among the CERAD subtests, verbal fluency had the worst accuracy, and word list learning had the best accuracy. Despite the limits of this study, the CERAD battery can be efficient for assessment of cognitive deficits in Parkinson's disease patients.
\end{abstract}

Keywords: Parkinson's disease; dementia; cognition

RESUMO

A Bateria Neuropsicológica do Consortium to Establish a Registry for Alzheimer's Disease (CERAD) foi criada para a avaliação da doença de Alzheimer (DA), mas é usada em várias demências. O objetivo deste estudo foi avaliar a efetividade dessa bateria na avaliação de pacientes com doença de Parkinson (DP). Foram avaliados 49 pacientes com DP sendo aplicadas CDR, como padrão-ouro e CERAD. Os pacientes foram divididos em dois grupos: com e sem demência, a partir dos critérios para DPP pela Movement Disorders Society. A curva ROC para - CERAD resultou em uma $A \cup C=0.989$ ( $95 \%$ Cl = 0.967 - 1, p<0.0001). Entre os subtestes do CERAD, fluência verbal obteve a pior acurácia, e aprendizado de lista de palavras, a melhor. Apesar das limitações do estudo, a bateria do CERAD pode ser uma ferramenta eficaz na avaliação de déficits cognitivos em pacientes com DP.

Palvras-chave: doença de Parkinson; demência; cognição

Parkinson's disease (PD) is a degenerative disorder in which motor changes are mainly as a result of the death of dopaminergic neurons in the substantia nigra. However, the changes are not restricted to this brain region and can be found in other nuclei of the brainstem, in the cerebral cortex and even in peripheral neurons, such as those in the myoenteric plexus. The presence of degenerative processes in the dopaminergic system and in different brain areas, for example the frontal lobe, can explain a series of non-motor signs and symptoms such as cognitive impairment and dementia ${ }^{1}$.

Parkinson's disease dementia (PDD) is a dysexecutive syndrome characterized by impaired planning, a deficit in executive function (including organization of goal-directed activities), dyspraxia, bradyphrenia, reduced problem-solving ability, learning difficulty and short-term memory loss. Most patients also present with concomitant fluctuations in attention, mood and personality, as well as hallucinations and psychoses ${ }^{2,3}$. Parkinson's disease dementia has a prevalence of $40 \%$ to $80 \%^{4}$, and the annual increase in risk is between $6 \%$ and $15 \%^{5}$. Cognitive decline is not limited to advanced PD stages and has been identified in $20 \%$ to $35 \%$ of patients recently diagnosed with $\mathrm{PD}$ or in the initial stages of the disease. This high prevalence and the major impact the condition has on the patient and family members make it essential

\footnotetext{
1 Universidade Estadual de Ponta Grossa, Hospital Universitário Regional dos Campos Gerais, Serviço de Neurologia, Ponta Grossa PR, Brasil; 
to detect and diagnose cognitive changes in $\mathrm{PD}$ patients as early as possible ${ }^{6}$. Risk factors for PDD are mild cognitive deficit, advanced age, late-onset PD, more severe motor symptoms, depression, long disease duration, akinetic-rigid syndrome and psychoses ${ }^{5,6}$. Parkinson's disease dementia is the most important risk factor for admission of PD patients to a nursing home. In addition, the risk of mortality for patients with PDD is higher than for patients without the condition?

The Consortium to Establish a Registry for Alzheimer's Disease (CERAD) neuropsychological battery was created in 1986 by the National Institute on Aging for the clinical assessment of cognitive changes in Alzheimer's disease (AD), including diagnosis and longitudinal assessment of cognitive deficits. Since it was created, the CERAD battery has been used to assess not only cognitive changes exclusive to $\mathrm{AD}$ but also a broad spectrum of other cognitive changes, PD, frontotemporal dementia and vascular dementia, for example $7,8,9,10,11,12$. The widespread use of this scale can be attributed to its very good inter-rater agreement, its retest reliability and its reliability when used for longitudinal follow-up assessments $^{8,9}$. We have been able to corroborate these findings in another study with $\mathrm{AD}$ patients ${ }^{13}$.

In light of the above, the present study sought to investigate the efficacy of using this tool in the PD patients' diagnosis and assessment.

\section{METHODS}

Forty-nine patients who had been seen at the neurology service, Campos Gerais Regional University Hospital, and INOVARE Serviços de Saúde Ltda., and who agreed to take part in the study, were selected in accordance with the Parkinson's Disease Society Brain Bank diagnostic criteria ${ }^{14}$. The ratio of males to females was 1.88:1. All the participants signed a voluntary informed-consent form.

The exclusion criteria, which were intended to exclude patients whose signs and symptoms made it impossible for them to perform a cognitive assessment or apply the proposed tests, were as follows: 1) advanced PD stage with severe motor impairment; 2) severe psychotic symptoms; 3) another dementia not associated with PD; and 4 patients who had cognitive changes that had started at least one year before motor symptoms (possible dementia with Lewy bodies) ${ }^{2}$. The study was approved by the State University of Ponta Grossa Research Ethics Committee (reference FA631.285).

All the patients were assessed during the ON phase of levodopa therapy; preferably two hours after the medication had been administered (ON phase $=$ stage with the effect of levodopa; OFF phase = stage without effect of levodopa). A team trained in movement disorders carried out the clinical assessment. A semi-structured questionnaire was applied to collect epidemiologic data, data about disease progression, previous and current treatment. Patients were classified according to motor changes on the Hoehn and Yahr scale ${ }^{15}$ and the Unified Parkinson's Disease Rating Scale III (UPDRS-III) ${ }^{16}$.

After the confirmation of diagnosis, the patients' cognition was assessed. All patients were assessed during the ON phase of levodopa and while they were using acetylcholinesterase inhibitors. The Clinical Dementia Rating Scale (CDR) was used to assess cognitive impairment in six areas: memory, orientation, judgement and problem solving, community affairs, home and hobbies, and personal care ${ }^{17}$. Patients scoring $\geq 1$ in at least two of the six CDR domains or those receiving a CDR-SOB (sum of boxes) score $\geq 3$ were classified as having cognitive impairment; patients scoring below these cutoff scores were classified as cognitively intact ${ }^{18}$. Among the patients with cognitive decline, PDD was diagnosed using the Movement Disorders Society criteria ${ }^{2,19}$.

A trained team also applied the CERAD neuropsychological battery ${ }^{8,9,10}$. This consists of seven subtests that together give a maximum score of 100 as follows: 1) verbal fluency; 2) modified Boston naming; 3) word list learning; 4) constructional praxis; 5) word list recall; 6) word list recognition; and 7) constructional praxis recall. In this study, unlike most authors, the Mini-Mental State Examination (MMSE) or clock drawing test were not added to the CERAD battery.

For the analysis, PD patients were divided into two groups, one with dementia and the other without. The data for both groups of patients were compared and tested to determine whether they had a normal or non-normal distribution pattern in the Shapiro-Wilk test. Statistical differences between the means of the groups were determined using the one-tailed Student's t-test for normal distributions and the Mann-Whitney test for non-normal distributions. Fisher's exact test was used to analyze the differences between the expected and observed values on two qualitative variables. All the statistical analysis was performed with Statistica for Windows (ver. 99) and Microsoft Office Excel 2010. The receiver operating characteristic (ROC) curve in Med Calc for Windows was used to calculate the sensitivity, specificity, and cutoff of the CERAD neuropsychological battery. The area under the curve (AUC) is equal to the probability that a variable will correctly classify a pair of individuals randomly chosen from two groups as belonging to their true category. An AUC = 1.0 indicates no overlap between groups and that the individuals will always be correctly classified, whereas AUC $=0.500$ indicates chance-level accuracy. Differences were considered significant when $\mathrm{p}<0.05$.

\section{RESULTS}

When using the Movement Disorders Society criteria, $33(67.3 \%)$ of the 49 patients were diagnosed with PDD and $16(32.7 \%)$ without. When the clinical and epidemiologic characteristics of the patients with dementia and those without were compared, the PDD patients had a lower schooling and a worse motor score on the UPDRS-III (Table 1). 
Table 1. Clinical and epidemiologic characteristics of Parkinson's disease patients with and without dementia.

\begin{tabular}{|c|c|c|c|c|}
\hline Variable & Total $(n=49)$ & With dementia $(n=33)$ & Without dementia $(n=16)$ & $p$-value \\
\hline Gender & $49(100 \%)$ & $33(67.3 \%)$ & $16(32.6 \%)$ & \\
\hline Female & $18(36.7 \%)$ & $13(39.4 \%)$ & $5(31.3 \%)$ & 0.7541 \\
\hline Male & $31(63.3 \%)$ & $20(60.6 \%)$ & $11(68.7 \%)$ & \\
\hline Age at onset of symptoms & $60.6 \pm 12.3$ & $62.3 \pm 11.6$ & $57.1 \pm 12.8$ & 0.0827 \\
\hline Disease duration & $8.9 \pm 8.3$ & $9.6 \pm 9.5$ & $7.7 \pm 4.2$ & 0.239 \\
\hline Duration of levodopa therapy & $5.5 \pm 5.1$ & $5.3 \pm 5.0$ & $6.7 \pm 5.8$ & 0.4326 \\
\hline Hoehn and Yahr & $2.3 \pm 1.2$ & $2.4 \pm 1.3$ & $2.1 \pm 1.0$ & 0.2382 \\
\hline UPDRS - III & $21.4 \pm 11.4$ & $24.4 \pm 11.4$ & $14.9 \pm 8.1$ & $0.002^{*}$ \\
\hline Schooling & $7.0 \pm 4.9$ & $5.9 \pm 4.6$ & $9.4 \pm 4.7$ & $0.0105 *$ \\
\hline
\end{tabular}

Age, age at onset of symptoms, schooling, disease duration and duration of levodopa therapy are all expressed in years. UPDRS-III: Unified Parkinson's Disease Rating Scale III. *Statistically significant value.
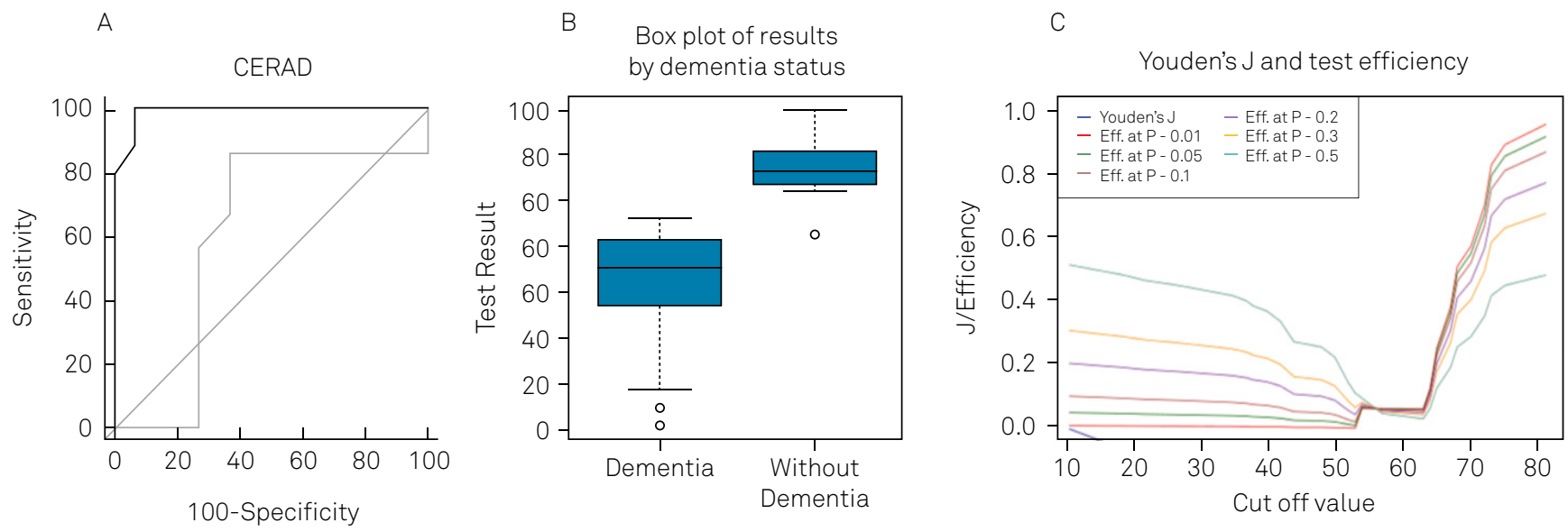

*Consortium to Establish a Registry for Alzheimer's Disease (CERAD) neuropsychological battery.

Figure. Comparison of Parkinson's disease patients by CERAD through the ROC Curve with Younden's J Index.

Using the CDR for dementia diagnosis as the gold standard, the ROC curve for the CERAD battery had an AUC $=0.989$ (95\% CI $=0.967-1, \mathrm{p}<0.0001)$ (Figure). Table 2 shows the sensitivity and specificity results for different CERAD cutoffs. The Youden index determined the score of 57 as an optimum cutoff for the CERAD (Figure).

An analysis of the ROC curve for accuracy showed a moderate accuracy (AUC = $0.7-0.9)$ in three CERAD subtests, and a high accuracy (AUC > 0.9) in seven subtests. Verbal fluency had the worst AUC, $0.754(95 \% \mathrm{CI}=0.610-0.866)$, and word list learning had the best, $0.937(95 \% \mathrm{CI}=0.828-0,986)$. The AUC and cutoff for each CERAD subtest were also calculated (Table 3).

\section{DISCUSSION}

Overall, $67.3 \%$ of the patients in this study were diagnosed with PDD. This number is close to the upper limit of the prevalence of PDD found in various earlier studies (25\% to $83 \%)^{4,20,21}$. This high prevalence in a cross-sectional study may be explained by the fact that the patients were followed up in a
Table 2. Cutoffs for the CERAD.

\begin{tabular}{lcc}
\hline Cutoff & Sensitivity (\%) & Specificity (\%) \\
\hline 52 & 78.8 & 100 \\
53 & 87.9 & 93.7 \\
54 & 90.9 & 93.7 \\
55 & 97.0 & 93.7 \\
$57 *$ & 100 & 93.7 \\
\hline * Younden's J Index; CERAD: & Consortium to Establish a Registry for \\
Alzheimer's Disease & &
\end{tabular}

tertiary care hospital and that their mean disease duration and complexity were greater than in other patient series.

Low schooling had a statistical correlation with dementia. This corroborates the findings reported in the literature, according to which a lack of education is a risk factor for dementia ${ }^{22}$. Old age, disease duration and progression of motor symptoms did not have a correlation with PDD. The Hoehn \& Yahr stage did not show significant differences between the patients with dementia and without dementia, 
Table 3. Comparison of PD patients, with and without dementia, by CERAD subtests.

\begin{tabular}{|c|c|c|c|c|c|}
\hline Test (Maximum score) & $\begin{array}{c}\text { With } \\
\text { dementia } \\
(n=33)\end{array}$ & $\begin{array}{l}\text { Without } \\
\text { dementia } \\
(n=16)\end{array}$ & $p$-value & AUC* & Cutoff** \\
\hline Verbal Fluency (13) & $9.97 \pm 3.1$ & $12.25 \pm 1.7$ & 0.0002 & $0.754(95 \% \mathrm{Cl}=0.610-0.866)$ & 12 \\
\hline Modified Boston Naming (15) & $8.73 \pm 2.9$ & $12.06 \pm 1.7$ & $<0.0001$ & $0.841(95 \% \mathrm{Cl}=0.708-0.930)$ & 9 \\
\hline Word List Learning (30) & $9.12 \pm 3.7$ & $15.75 \pm 2.9$ & $<0.0001$ & $0.937(95 \% \mathrm{Cl}=0.828-0,986)$ & 12 \\
\hline Constructional Praxis (11) & $4.70 \pm 2.7$ & $8.16 \pm 2.0$ & $<0.0001$ & $0.836(95 \% \mathrm{Cl}=0.703-0.926)$ & 5 \\
\hline Word List Recall (10) & $1.89 \pm 1.6$ & $5.06 \pm 1.4$ & $<0.0001$ & $0.929(95 \% \mathrm{Cl}=0.818-0,983)$ & 4 \\
\hline Word List Recognition (10) & $4.97 \pm 3.0$ & $7.5 \pm 1.5$ & 0.0001 & $0.759(95 \% \mathrm{Cl}=0.615-0.869)$ & 5 \\
\hline Constructional Praxis Recall (10) & $2.94 \pm 2.5$ & $7.44 \pm 2.2$ & $<0.0001$ & $0.903(95 \% \mathrm{Cl}=0.785-0.969)$ & 4 \\
\hline
\end{tabular}

unlike that in the UPDRS scale. These findings do not concur with the results of a study by Zhu et al..$^{23}$, in which patients with dementia were older and had a longer disease duration and higher Hoehn \& Yahr stage ${ }^{7.24}$. Karrasch et al. ${ }^{18}$ found patients with cognitive decline with worse motor scores in the UPDRS and Hoeh \& Yahr, and with a longer disease duration, but there was no difference in schooling between patients with PD with and without dementia. These contradictory findings may be due to the small number of patients without dementia in our study, most of whom were an advanced age ( $69.3 \pm 11.4$ years). In addition, a very important factor was the time when the patients were assessed. In our series, this was done during the ON phase (with the effect of levodopa), when the patients' motor skills were at their best. If the patients were evaluated during the OFF phase, the results may have been similar to those of other studies.

The results suggest that the CERAD may have the necessary efficacy and accuracy for the evaluation of cognition in PD patients. This neuropsychological battery has been used worldwide, not only in $\mathrm{AD}$, but also for various types of dementias, as it includes a wide range of subtests ${ }^{18,25,26,27}$. The cognitive functions most affected in PD are executive functions, attention and memory. However, other cortical functions such as visuospatial functions, orientation and perception are also affected ${ }^{25}$. Although the seven main subtests are almost always present, there are variations in the CERAD battery. In the CERAD Brazilian validation with $\mathrm{AD}$ patients, Bertolucci et al..$^{10}$ added the MMSE (cutoff $=85$, and 59 without MMSE). In the version used by Karrasch et al. ${ }^{18}$ for PD patients, the clock drawing test was added. We preferred to test using the version without the MMSE or clock drawing test. Our cutoff was 57 , very close to the Brazilian study with $\mathrm{AD}$ patients ${ }^{10}$.

One of the difficulties in using the traditional seven subtests of the CERAD in PD patients is that the only CERAD subtest for executive functions assessment is the verbal fluency test. These cognitive domains are affected in PDD, quite often more severely than in $\mathrm{AD}^{28}$. Verbal fluency was the subtest with the worst accuracy in our study. Tedrus et al. ${ }^{27}$ reported similar findings. In the study by Karrash et al. ${ }^{18}$, the authors attempted to overcome the lack of tests assessing frontostriatal functions in the CERAD by adding the clock drawing test. However, the accuracy of both subtests was also lower ${ }^{18}$. Like executive functions, visuospatial functions are compromised in PDD, a finding that tends to be more frequent in $\mathrm{PDD}$ patients than in $\mathrm{AD}$ patients ${ }^{28}$. Visuospatial function was assessed by the constructional praxis test in the CERAD; however, this subtest had moderate accuracy and it was poorly sensitive for visuospatial deficits. Karrash et al. ${ }^{18}$ also showed moderate accuracy for this subtest.

The CERAD naming test assesses language function, which has already been shown to be impaired in PD patients, although to a lesser extent than in $\mathrm{AD}$ patients ${ }^{7}$. The difference in the results of the naming test for the two groups was statistically significant, despite the moderate accuracy, unlike in the study by Karrasch et al ${ }^{18}$. Initially, these discordant findings could be attributed to social and cultural differences in the populations studied, because some images are not familiar to some Brazilian subjects (e.g., ice tongs). However, in the study by Bertolucci et al. ${ }^{10}$, in which the CERAD battery was validated for Brazilian Portuguese, the control group displayed good performance in identifying the images, achieving a mean of 13.1 out of a maximum score of 15 in the naming test. We tried to find differences other than the cultural backgrounds between our patients and those of Karrasch et al. ${ }^{18}$, but the samples from the two studies were similar in age and level of symptom progression. Nevertheless, the level of education was considerably lower in the Brazilian group. Thus, the combination of advanced age and, mainly, low school level may help in the understanding of these scores.

In the CERAD subtests that assess memory (word list learning, word list recall, word list recognition and constructional praxis recall), patients with PDD performed worse than those without dementia. In the study by Karrasch et al. ${ }^{18}$ only the result for word list learning was statistically significant, and in the study by Tedrus et al..$^{27}$ none of the differences in the results of the subtests were statistically significant. These subtests are extremely sensitive to changes in episodic verbal memory ${ }^{29}$. A decline in episodic verbal memory may be the strongest indication of incipient dementia in PD patients ${ }^{6}$. Memory abilities have already been reported to be impaired in $\mathrm{PDD}$ patients, although to a lesser extent than in $\mathrm{AD}$ patients. The CERAD battery provides a more accurate assessment of 
memory deficits than specific tests for PD patients, such as the Scales for Outcomes in Parkinson's disease-Cognition ${ }^{28,29}$.

We have reported a number of limitations of our study; however, we can state that our data suggest the possibility of the CERAD neuropsychological battery being used to evaluate PD patients with cognitive deficits. The large number of cognitive domains comprised in this battery makes it a powerful diagnostic tool. We would like to see further studies, with a greater number of patients, being able to prove the issues that our study introduces.

\section{References}

1. Lees AJ, Hardy J, Revesz T. Parkinson's disease. Lancet. 2009 Jun;373(9680):2055-66. https://doi.org/10.1016/S0140-6736(09)60492-X

2. Emre M, Aarsland D, Brown R, Burn DJ, Duyckaerts C, Mizuno Y et al. Clinical diagnostic criteria for dementia associated with Parkinson's disease. Mov Disord. 2007 Sep;22(12):1689-707. https://doi.org/10.1002/mds.21507

3. Aarsland D, Bronnick K, Williams-Gray C, Weintraub D, Marder K, Kulisevsky J et al. Mild cognitive impairment in Parkinson disease: a multicenter pooled analysis. Neurology. 2010 Sep;75(12):1062-9. https://doi.org/10.1212/WNL.0b013e3181f39d0e

4. Hely MA, Reid WG, Adena MA, Halliday GM, Morris JG. The Sydney multicenter study of Parkinson's disease: the inevitability of dementia at 20 years. Mov Disord. 2008 Apr;23(6):837-44. https://doi.org/10.1002/mds.21956

5. Janvin CC, Larsen JP, Aarsland D, Hugdahl K. Subtypes of mild cognitive impairment in Parkinson's disease: progression to dementia. Mov Disord. 2006 Sep;21(9):1343-9. https://doi.org/10.1002/mds.20974

6. Goldman JG, Litvan I. Mild cognitive impairment in Parkinson's disease. Minerva Med. 2011 Dec;102(6):441-59.

7. Emre M. Dementia associated with Parkinson's disease. Lancet Neurol. 2003 Apr;2(4):229-37. https://doi.org/10.1016/S1474-4422(03)00351-X

8. Fillenbaum GG, van Belle G, Morris JC, Mohs RC, Mirra SS, Davis $P C$ et al. Consortium to establish a registry for Alzheimer's disease (CERAD): the first twenty years. Alzheimers Dement. 2008 Mar;4(2):96-109. https://doi.org/10.1016/j.jalz.2007.08.005

9. Rossetti HC, Munro Cullum C, Hynan LS, Lacritz LH. The CERAD neuropsychologic battery total score and the progression of Alzheimer disease. Alzheimer Dis Assoc Disord. 2010 AprJun;24(2):138-42. https://doi.org/10.1097/WAD.0b013e3181b76415

10. Bertolucci PH, Okamoto IH, Brucki SM, Siviero MO, Toniolo Neto J, Ramos LR. Applicability of the CERAD neuropsychological battery to Brazilian elderly. Arq Neuropsiquiatr. 2001 Sep;59 3-A:532-6. https://doi.org/10.1590/S0004-282X2001000400009

11. Bilello M, Doshi J, Nabavizadeh SA, Toledo JB, Erus G, Xie SX et al. Correlating cognitive decline with white matter lesion and brain atrophy magnetic resonance imaging measurements in Alzheimer's disease. J Alzheimers Dis. 2015;48(4):987-94. https://doi.org/10.3233/JAD-150400

12. Haanpää RM, Suhonen NM, Hartikainen P, Koivisto AM, Moilanen V, Herukka SK et al. The CERAD neuropsychological battery in patients with frontotemporal lobar degeneration. Dement Geriatr Cogn Dis Extra. 2015 Apr;5(1):147-54. https://doi.org/10.1159/000380815

13. Camargo $\mathrm{CH}$, Justus FF, Retzlaff $\mathrm{G}$. The effectiveness of reality orientation in the treatment of Alzheimer's disease. Am J Alzheimers Dis Other Demen. 2015 Aug;30(5):527-32. https://doi.org/10.1177/1533317514568004

14. Daniel SE, Lees AJ. Parkinson's Disease Society Brain Bank, London: overview and research. J Neural Transm Suppl. 1993;39:165-72.

15. Hoehn MM, Yahr MD. Parkinsonism: onset, progression and mortality. Neurology. 1967 May;17(5):427-42. https://doi.org/10.1212/WNL.17.5.427

16. Goetz CG, Tilley BC, Shaftman SR, Stebbins GT, Fahn S, MartinezMartin P et al. Movement Disorder Society-sponsored revision of the Unified Parkinson's Disease Rating Scale (MDS-UPDRS): scale presentation and clinimetric testing results. Mov Disord. 2008 Nov;23(15):2129-70. https://doi.org/10.1002/mds.22340

17. Morris JC. The Clinical Dementia Rating (CDR): current version and scoring rules. Neurology. 1993 Nov;43(11):2412-4. https://doi.org/10.1212/WNL.43.11.2412-a

18. Karrasch M, Laatu S, Martikainen K, Marttila R. CERAD test performance and cognitive impairment in Parkinson's disease. Acta Neurol Scand. 2013 Dec;128(6):409-13. https://doi.org/10.1111/ane.12138

19. Kiesmann M, Chanson JB, Godet J, Vogel T, Schweiger L, Chayer S et al. The Movement Disorders Society criteria for the diagnosis of Parkinson's disease dementia: their usefulness and limitations in elderly patients. J Neurol. 2013 Oct;260(10):2569-79. https://doi.org/10.1007/s00415-013-7018-8

20. Riedel O, Klotsche J, Spottke A, Deuschl G, Förstl H, Henn F et al. Cognitive impairment in 873 patients with idiopathic Parkinson's disease results from the German study on epidemiology of Parkinson's disease with dementia (GEPAD). J Neurol. 2008 Feb;255(2):255-64. https://doi.org/10.1007/s00415-008-0720-2

21. Buter TC, van den Hout A, Matthews FE, Larsen JP, Brayne C, Aarsland D. Dementia and survival in Parkinson disease: a 12-year population study. Neurology. 2008 Mar;70(13):1017-22. https://doi.org/10.1212/01.wnl.0000306632.43729.24

22. Aarsland D, Andersen K, Larsen JP, Lolk A, Nielsen H, Kragh-Sørensen P. Risk of dementia in Parkinson's disease: a community-based, prospective study. Neurology. 2001 Mar;56(6):730-6. https://doi.org/10.1212/WNL.56.6.730

23. Zhu K, van Hilten JJ, Marinus J. Predictors of dementia in Parkinson's disease; findings from a 5-year prospective study using the SCOPA-COG. Parkinsonism Relat Disord. 2014 Sep;20(9):980-5. https://doi.org/10.1016/j.parkreldis.2014.06.006

24. Levy G, Jacobs DM, Tang MX, Côté LJ, Louis ED, Alfaro B et al. Memory and executive function impairment predict dementia in Parkinson's disease. Mov Disord. 2002 Nov;17(6):1221-6. https://doi.org/10.1002/mds.10280

25. Marinus J, Visser M, Verwey NA, Verhey FR, Middelkoop HA, StiggelboutAM et al. Assessment of cognition in Parkinson's disease. Neurology. 2003 Nov;61(9):1222-8. https://doi.org/10.1212/01.WNL.0000091864.39702.1C

26. Wolfsgruber S, Jessen F, Wiese B, Stein J, Bickel H, Mösch E et al.The CERAD neuropsychological assessment battery total score detects and predicts Alzheimer disease dementia with high diagnostic accuracy. Am J Geriatr Psychiatry. 2014 Oct;22(10):1017-28. https://doi.org/10.1016/j.jagp.2012.08.021

27. Tedrus GM, Fonseca LC, Letro GH, Bossoni AS, Samara AB. Dementia and mild cognitive impairment in patients with Parkinson's disease. Arq Neuropsiquiatr. 2009 Jun;67(2b 2B):423-7. https://doi.org/10.1590/S0004-282X2009000300010

28. Stern Y, Richards M, Sano M, Mayeux R. Comparison of cognitive changes in patients with Alzheimer's and Parkinson's disease. Arch Neurol. 1993 Oct;50(10):1040-5. https://doi.org/10.1001/archneur.1993.00540100035011

29. Helkala EL, Laulumaa V, Soininen H, Riekkinen PJ. Different error pattern of episodic and semantic memory in Alzheimer's disease and Parkinson's disease with dementia. Neuropsychologia. 1989;27(10):1241-8. https://doi.org/10.1016/0028-3932(89)90036-5 